\title{
Postharvest Flux and Genotype $\times$ Environment Effects for Onion-induced Antiplatelet Activity, Pungency, and Soluble Solids in Long-day Onion during Postharvest Cold Storage
}

\author{
J.E.P. Debaene, ${ }^{1}$ I.L. Goldman, ${ }^{2}$ and B.S. Yandell ${ }^{3}$ \\ Department of Horticulture, 1575 Linden Drive, University of Wisconsin, Madison, WI 53706
}

AdDitional INDEX words. Allium cepa, antiplatelet, antithrombotic, functional food

\begin{abstract}
Two mild and two pungent onion (Allium cepa L.) selections (hereafter referred to as cultitypes), W420B, W424B, MSU8155B, and Exhibition, were grown at two locations in two states (Wisconsin and Oregon) during 1994 and 1995. Onion bulbs were harvested, stored at $4^{\circ} \mathrm{C}$ and sampled for antiplatelet activity, pungency, and soluble solids 10 days after harvest and every 40 days during a 210-day postharvest storage period. Significant cultitype $\times$ state and cultitype $\times$ year interactions were detected. However, these were primarily due to the change in rank of cultitypes within the mild or pungent group. Averaged over all environments, antiplatelet activity was significantly greater in 1994 compared to 1995 for all cultitypes. Significantly greater antiplatelet activity was measured for three out of four cultitypes grown in Oregon compared to Wisconsin. During postharvest storage, antiplatelet activity increased $61 \%$ and $56 \%$ across all cultitypes and across both states during 1994, and across all cultitypes in Wisconsin during 1995, respectively. Although pungency determination can be a good indicator for relative rankings of different cultitypes for antiplatelet activity, changes in pungency were not correlated with changes in antiplatelet activity during postharvest storage. Results demonstrate cultitype, environment, duration of postharvest storage and genotype $\times$ environment interactions influence pungency, soluble solids, and antiplatelet activity, which should be considered when assessing onion-induced antiplatelet activity.
\end{abstract}

Allium species have historically been used by many cultures in folk medicine and in traditional cuisine (Augusti, 1990; Block, 1992; Lawson, 1993). Onion has been suggested as a treatment for a variety of human ailments. Native onion sulfoxides have lipidlowering effects, fibrinolytic effects, and antiplatelet activity (Augusti, 1990). Platelet aggregation contributes to the risk of thromboembolic diseases due to agglutination and fusion of blood platelets obstructing the flow of blood in vessels supplying organs or tissues (Mustard and Packham, 1970). Several Allium-derived compounds have an inhibitory effect on platelet aggregation and may potentially be used to treat or prevent thromboembolic conditions.

Organosulfur compounds responsible for the distinct aromas and flavors in onion are synthesized from a common precursor, the Salk(en)yl-L-cysteine sulfoxides (ACSOs). Upon crushing of onion bulb tissue, the ACSOs are hydrolyzed by alliinase into a suite of thiosulfinates (Lancaster and Shaw, 1989). Concentration of ACSO and alliinase varies with onion cultivar and is also influenced by environmental factors (Lancaster and Shaw, 1989; Randle, 1992). Pungency, an indicator of the strength

of onion flavor, is commonly measured by the pyruvic acid method (Randle and Bussard, 1993b; Schwimmer and Weston, 1961) in which reaction of 2,4-dinitro phenyl-hydrazine (DNPH) with $\mathrm{NaOH}$ is used to detect the presence of pyruvic acid. In one of the earliest studies addressing the effects of environment and cultivar on onion pungency, investigators observed that, although cultivar has the most pronounced effect, genotype $\times$ environment effects were important in explaining variability (Platenius and

Received for publication 5 June 1998. Accepted for publication 12 Apr. 1999. The cost of publishing this paper was defrayed in part by the payment of page charges. Under postal regulations, this paper therefore must be hereby marked advertisement solely to indicate this fact.

${ }^{1}$ Former graduate research assistant. Current address: Department of Crop Sciences, University of Illinois, Urbana, IL 61801

${ }^{2}$ Associate professor; to whom reprint requests should be addressed.

${ }^{3}$ Professor, Department of Statistics and Department of Horticulture.
Knott, 1934). In a study by Randle (1992), pungency ranged from 1.6 for mild to $13.0 \mu \mathrm{mol}$ pyruvate/g fresh weight for pungent onions, depending on the cultivar and sulfur substrate conditions (Randle, 1992). Since organosulfur compounds responsible for antiplatelet activity and pungency are synthesized from a common precursor, the ACSOs (Block, 1992), pungency may be an indicator of antiplatelet activity.

Previous studies have evaluated the relationship between total dissolved solids (TDS) and total dry matter with pungency (Bedford, 1984; Randle, 1992). Higher TDS tend to be correlated with higher pungency and a correlation with increased antiplatelet activity can behypothesized. Solids contribute to the flavor, texture, and storability of onions. Solids are measured by the refractive index of onion extract on a refractometer and are highly correlated $\left(r^{2}=0.96\right)$ to dry matter content (Mann and Hoyle, 1945). High levels of TDS in onions are desirable for dehydration and in certain cases are associated with good storability. Storability, the maintenance of high quality onion bulbs during storage, is of great importance to both producers and consumers of onions since onions are generally stored at temperatures slightly $>0{ }^{\circ} \mathrm{C}$ after harvest so they can be sold at favorable market prices during the winter months. Studies relating dry matter content and storage characteristics have shown that high dry matter content is related to good storability (Suzuki and Cutliffe, 1989). Total dry matter percentage values of various onion cultivars ranged from 3.03 to $20.10 \mathrm{~g}$ per $100 \mathrm{~g}$ bulb material, depending on sulfur conditions of growth media and phenotype (Randle, 1992). High sulfur substrate conditions increased pungency in cultivars with high pyruvic acid measurements but were associated with reduced dry matter or TDS measurements (Randle and Bussard, 1993a, 1993b). Postharvest changes in these variables have been documented in several studies as the ratios of organosulfur compounds, pungency and solids change during storage and also depend on storage temperature, time of harvest, cultivar, and postharvest handling before storage (Hurst et al., 1985; Kopsell and Randle, 1997; Miedema, 1994; Mikitzel and Fellman, 1994). 
Genotype $\times$ environment interactions are of great interest when evaluating stability of combining ability of breeding lines across different environmental conditions. However, they have received little attention in onion. In an evaluation of a seven parent onion diallel cross for general and specific combining ability (GCA and SCA, respectively) and their environmental interactions, second order interactions of GCA $\times$ years $\times$ locations were attributed to genotype $\times$ environment interactions (Hosfield et al., 1977). Similar observations in onion were also reported by Utkhede et al. (1982). Quercitin, a flavonoid associated with significant health functionality, exhibited significant genotype $\times$ environment interaction due to changes in rank among cultivars grown in two Texas locations (Patil et al., 1995a). These studies suggest that chances of increased genotype $\times$ environment are usually more prevalent with more complex traits when tested over a wide variety of environments.

Many onion cultivars are specifically grown for storage so they can be sold during the winter months in the United States. Postharvest handling and storage conditions can affect bulb physiology and respiration rates. Significant changes in the concentration of quercetin in the cultivar TG1015Y were observed during a 5 month storage period at four different storage regimes (Patil et al., 1995). These changes were attributed to physiological changes of the bulbs during storage. It has been demonstrated that pungency and solids change during storage and that this response is cultivar dependent (Hanum et al., 1995; Kopsell and Randle, 1997; Suzuki and Cutliffe, 1989). Hanum et al. (1995) reported that alliinase activity, transpeptidase activity and consequently pyruvate content increased in one cultivar during a 32 week storage period at room temperature. Lancaster and Shaw (1991) demonstrated changes in ACSO ratios during onion bulb storage. Because alliinase is the enzyme that hydrolyzes the ACSOs to form thiosulfinates, which in turn inhibit platelet aggregation, it is reasonable to hypothesize that storage duration can affect antiplatelet activity.

To date, no studies have been conducted to investigate the effect of long-term cold storage on antiplatelet activity. In addition, although Augusti et al. (1975) noted that fibrinolytic activity varied between 'Spanish' and 'English' type onions and Goldman et al. (1995) reported significant differences in antiplatelet strength among Allium species and species accessions, there are no investigations that focus on the environmental aspects and within species or intercultivar variation of antiplatelet activity. Therefore, the objective of this study was to examine the effect of several environmental parameters on onion-induced antiplatelet activity during the postharvest storage period. Further, we sought to examine the correlation among pungency, solids, and antiplatelet activity to determine if these commonly measured bulb characters could be used as a predictor for estimating antiplatelet activity across environments and during the postharvest period.

\section{Materials and Methods}

Commercial varieties, hybrids, open pollinated populations, released inbred lines or experimental lines are often used within the same study in horticultural research. To simplify the terminology for discussing these collectively, the term cultitype was used.

Four onion cultitypes from different origins or populations were selected for this study. Two cultitypes were mild flavored and had low pungency: 'Exhibition' (Bejo Seed Company, Holland) and MSU8155B(U.S. Dept. Agr., Agr. Res. Serv.). Exhibition, an openpollinated cultivar, is characterized by its large size, high water content, and mild flavor. MSU8155B, an inbred line released by C.E. Peterson of the USDA, Agr. Res. Serv.in 1982, is characterized by low pungency and is valued as a parent of mild-flavored onion hybrids. The other two cultitypes, W434B and W420B, are pungent inbred lines released by W. H. Gabelman at the University of Wisconsin-Madison in 1990 and 1983, respectively, and are characterized by good storage quality, high pungency and high solids.

Onion bulbs were grown from seed at four locations during 1994 and 1995. Two locations were in Lake Labish and Brooks, Oregon, and two locations were in Randolph, Wisconsin, at two different farms. Oregon and Wisconsin were selected to represent different climatic conditions for long day onions, and within those states, two locations were selected. A randomized complete block design was used in each state with four replications at each of the two Wisconsin locations and two replications at each of the Oregon locations. Within each replication, cultitypes were randomly assigned to a plot and replications randomly assigned to each location. The onions were sown in the two inner rows of four-row plots, $4.2 \mathrm{~m}$ in length at the Wisconsin locations. The outer rows were border rows of the commercial hybrid cultivar 'Fortress', provided by the Asgrow Seed company, DeForest, Wis. Onion bulbs were harvested at vegetative maturity based on the physiological stage when a minimum of $50 \%$ of the foliage leaves were collapsed. This is a standard developmental stage used by onion workers in the midwestern United States for date of maturity. At harvest, bulbs were collected and stored in mesh bags in a $4{ }^{\circ} \mathrm{C}$ cooler. Randle (1992) demonstrated two replications and five-bulb samples were adequate to detect a $1 \mu \mathrm{mol}$ difference in enzymatically developed pyruvic acid concentrations in onion. Thus, an equal representation of five bulbs per replication from each of the cultitypes were randomly selected and bulked every $40 \mathrm{~d}$, starting from $10 \mathrm{~d}$ until $210 \mathrm{~d}$ after harvest. For the purpose of evaluating genotype $\times$ environment interactions, we analyzed data from 50 to $170 \mathrm{~d}$ in postharvest storage, which corresponds to the time of the commercial storage season in the upper midwestern United States (Table 1). For the purpose of evaluating changes in antiplatelet activity and pungency and related interactions during the postharvest storage period, we increased the length of the postharvest storage period and analyzed data from 10 to $210 \mathrm{~d}$ postharvest. Dry outer scales were removed to correspond with typical culinary usage, bulbs were quartered along the longitudinal axis to obtain a balanced representation of outer and inner scales, and from the bottom to the neck of the bulb. One quarter of each of the five bulbs were macerated with a mechanical juicer for $20 \mathrm{~s}$ and the extract was collected and left on the bench at $25^{\circ} \mathrm{C}$ for $30 \mathrm{~min}$ to encourage enzymatic hydrolysis of the ACSO. Extract preparation was carried out as described in Goldman et al. (1996).

Platelet aggregation was assessed using thawed onion extract from the samples described above. Blood was drawn into citric acid anticoagulant from healthy subjects who abstained from eating any Allium species or platelet-inhibitory medicines for at least $36 \mathrm{~h}$ and from aspirin for $7 \mathrm{~d}$. Platelet rich plasma (PRP) was prepared from blood via centrifugation as described by Schwartz and Monroe (1986). Platelet aggregation was measured using the standard photometric technique with a platelet aggregometer described by Born and Cross (1963) and modified by Goldman et al. (1996). Fifty microliters of a standard platelet agonist (ADP) was added at a concentration of $10 \mathrm{~mm}$ to platelet suspensions as a stimulus of platelet aggregation. As a control, an ADP solution was substituted for Allium extract, keeping all other factors the same. Aggregation was documented with an attached recording device. Data were recorded as height of the curve in $\mathrm{mm}$ for $2 \mathrm{~min}$ following addition of ADP. Data from replicate samples were converted with the arcsine square root transformation.

Samples were analyzed for pyruvic acid content as described by 
Schwimmer and Weston (1961). Color development was measured at $420 \mathrm{~nm}$ on a spectrophotometer and $\mu \mathrm{M}$ of pyruvic acid per $\mathrm{mL}$ of juice was calculated based on a calibration curve obtained by measuring pyruvic acid standards simultaneously with the samples as outlined by Schwimmer and Weston (1961). Total pyruvic acid values were recorded. A drop of the same onion extract used for antiplatelet activity was used for measurement of solids with a refractometer at ambient temperature (Mann and Hoyle, 1945).

Data were analyzed with the MIXED procedure of SAS (Littell et al., 1996), to account for the fixed and random terms within the model, missing data, and the unbalanced design. The MIXED procedure of SAS is based on likelihood probabilities and is more accurate than the general linear model in computing estimates to determine significance among main effects and interactions in the model for unbalanced designs and when dealing with missing data. Replications within locations were considered random and all other terms within the model were considered fixed. Because sampling dates can be considered a repeated measure over time, the whole data set was first analyzed as a repeated measurement experiment, but because of the complex and unbalanced design and missing data, the SAS program could not be executed. Subsequent analyses were performed on subsets of the data and no substantial differences were observed among analyses with or without repeated measures. The final analysis on the whole data set was thus performed assuming independent probabilities among dates during postharvest storage. Replications nested within the proper interactions were put in the random statement of the MIXED procedure which determined the pertinent error term for testing the model. Higher order interactions which were nonsignificant across all analyses for antiplatelet activity, pungency, and soluble solids were removed from the model and the simplified model was reanalyzed. MIXED covariance analyses were performed to investigate correlations among onion-induced antiplatelet activity and pungency, antiplatelet activity and soluble solids, antiplatelet activity and average fresh weights, and antiplatelet activity with pungency and soluble solids combined. Only the noteworthy covariance analysis is reported and discussed. Replications nested within location $\times$ state and replication nested within location $\times$ state $\times$ line were intended as error terms to test the model. However, because the error terms were zero based on results from the MIXED analysis, tests of all terms within the model were performed with the residual as error. Because of the nested factors within the design, a simple coefficient of variation was inadequate to document the variability for the whole experiment. For this purpose, means with $95 \%$ confidence intervals were calculated for the significant and appropriate terms of the model. Comparisons among cultitype, state, and year means were made using least significant difference from the least squares means output from the MIXED procedure. A probability level of $P<0.05$ was used to declare significance for means comparison in this experiment, unless otherwise indicated.

\section{Results and Discussion}

INTERACTIONS OF CULTITYPE WITH YEAR AND STATE. The MIXED analysis revealed significant differences for antiplatelet activity among cultitypes between years, states, and date of sampling (Table 1). The cultitype $\times$ state interaction was significant at $P<0.05$ but was due to changes in rank between MSU8155B and Exhibition. In general the two milder cultitypes (MSU8155B and Exhibition) grouped together as did the pungent cultitypes (W420B and W434B) (Fig. 1). The analysis also revealed significance for the year $X$ cultitype interaction at $P<0.05$ for antiplatelet activity and can be attributed to changes in rank between W434B and W420B (Fig. 2). Cultitype was the largest contributing factor in an investigation assessing different components imparting variation of total quercetin concentration, an anticarcinogenic flavonoid, among several onion cultitypes (Patil et al., 1995a, 1995b). Previous research has illustrated that onion cultitypes from various sources produce varied amounts of enzymatically formed pyruvate (EPY), a standard measure of pungency (Randle, 1992). EPY may also be indicative of ACSO concentrations and alliinase activity (Randle et al., 1995). Following hydrolysis of the ACSO, sulfenic acids react spontaneously to form organosulfur compounds, including thiosulfinates and disulfides (Block, 1992; Lancaster and Boland, 1990). The former compounds have proven antiplatelet activity (Kawakishi and Morimitsu, 1994; Morimitsu and Kawakishi, 1990). Our results are consistent with findings that high levels of EPY seem to be associated with high levels of ACSO and enzymatic activity, because EPY was also associated with high levels of antiplatelet activity in our experiments.

Averaged over locations, antiplatelet activity was significantly higher in 1994 compared to 1995 for all cultitypes: $21.6 \%, 24.5 \%$, $35.3 \%$, and $45.8 \%$ for MSU8155B, Exhibition, W420B and W434B respectively (Fig. 2). This illustrates the effect of growing conditions in a given year and their effect on antiplatelet activity. It is of importance to note that the mild and pungent cultitypes group together, and that no change in rank occurred between the mild and pungent cultitypes averaged over storage duration. Significant differences among years and year $\times$ cultitype interactions for pungency were observed in an investigation to assess environmental effects on yield and flavor among six short-day onion cultitypes (Vavrina and Smittle, 1993). Pairwise comparisons of cultitypes averaged over years and states revealed significant differences between the mild and pungent cultitypes for antiplatelet activity. MSU8155B and 'Exhibition' exhibited an average of 24.7\% less antiplatelet activity than W420B and W434B (Table 2). This suggests that pungent cultitypes have consistently higher antiplatelet activity in comparison to milder cultitypes, supporting previous

Table 1. Overall mixed analysis of fixed effects for investigation of environmental and postharvest effects on onion-induced antiplatelet activity.

\begin{tabular}{lccc}
\hline \hline Source of variation & NDF $^{\mathrm{z}}$ & DDF $^{\mathrm{y}}$ & Type III F \\
\hline State & 1 & 12 & $18.15^{\text {**** }}$ \\
Location (state) & 2 & 12 & $8.43^{\text {*** }}$ \\
Year & 1 & 261 & $129.55^{\text {**** }}$ \\
State $\times$ year & 1 & 261 & $0.08^{\text {Ns }}$ \\
Year $\times$ location $($ state) & 2 & 261 & $0.19^{\text {NS }}$ \\
Date & 3 & 261 & $17.13^{\text {**** }}$ \\
State $\times$ date & 3 & 261 & $26.18^{\text {**** }}$ \\
Location $\times$ date $($ state $)$ & 6 & 261 & $2.46^{*}$ \\
Year $\times$ date & 3 & 261 & $82.31^{\text {**** }}$ \\
State $\times$ year $\times$ date & 3 & 261 & $5.57^{\text {**** }}$ \\
Year $\times$ location $\times$ date $($ state $)$ & 6 & 261 & $5.1^{* * * *}$ \\
Cultitype & 3 & 48 & $24.72^{\text {**** }}$ \\
State $\times$ cultitype & 3 & 48 & $4.11^{*}$ \\
Cultitype $\times$ date & 9 & 261 & $1.11^{\text {Ns }}$ \\
State $\times$ cultitype $\times$ date & 9 & 261 & $1.88^{\text {NS }}$ \\
Year $\times$ cultitype & 3 & 261 & $4.15^{* * *}$
\end{tabular}

${ }^{\mathrm{z}} \mathrm{NDF}=$ normal degrees of freedom.

${ }^{\mathrm{y}} \mathrm{DDF}=$ degrees of freedom used by the mixed analysis procedure.

Ns, ${ }^{*}, * * * * * * N$ Nonsignificant or significant at $P \leq 0.05,0.01$ or 0.001 , respectively. 

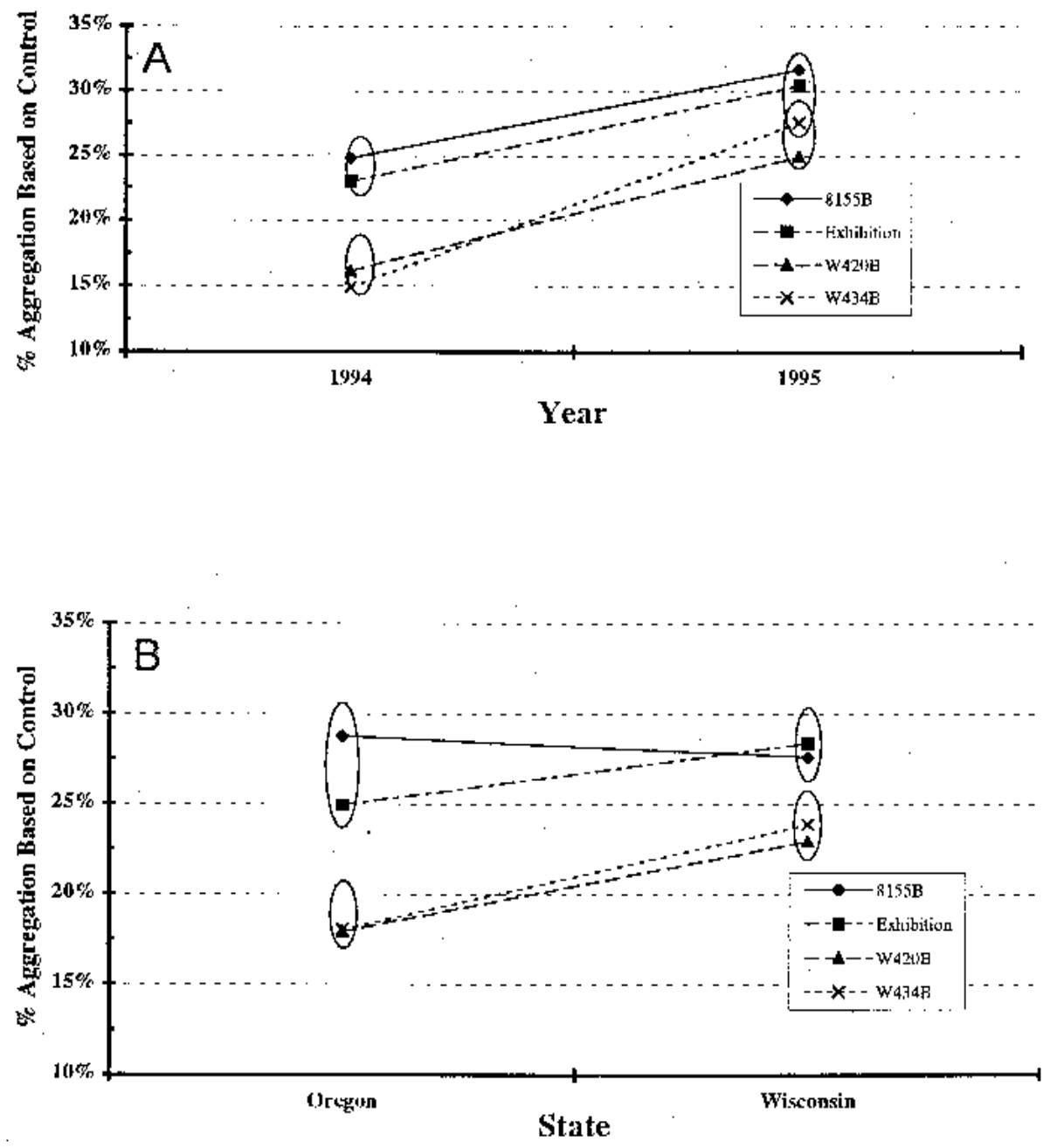

Fig. 1. Mean antiplatelet activity of onion cultitype bulb extracts by state averaged over years (A) and by year averaged over states $(\mathbf{B})$. Least significant means were calculated and pooled over the $120 \mathrm{~d}$ postharvest storage period, states, locations within states, and replications within locations. Antiplateletactivity was measured by percentaggregation in proportion to a non-onion control. For $\mathbf{A}$, Least significantmeans were calculated and pooled over the $120 \mathrm{~d}$ postharvest storage period, years, locations within states, and replications within locations. For $\mathbf{A}$ and $\mathbf{B}$, Ellipses around data points indicate nonsignificance at $P<0.01$ within states, based on the least square means analysis, among the cultitypes included in the ellipse.

work that pungency is positively correlated with antiplatelet activity (Goldman et al., 1996). Notwithstanding environmental interactions, these data indicate that mild onion cultitypes have consistently less antiplatelet activity compared to pungent cultitypes across different years.

Antiplatelet activity was significantly higher as induced by Oregon-grown bulbs compared to Wisconsin-grown bulbs for three out of four cultitypes: $3.4 \%, 5.0 \%$, and $5.8 \%$ for 'Exhibition', W420B and W434B respectively (Fig. 1). Differences among states for volatile organosulfur contents of onion bulbs has long been established (Platenius and Knott, 1934) and soil sulfate concentration has in part been attributed to cause variation in bulb pungency (Freeman and Mossadeghi, 1970).

The analysis also revealed a significant main effect of year. Averaged over states, antiplatelet activity was significantly higher in 1994 compared to 1995 (Fig. 2). However, the state $\times$ year interaction was not significant. Averaged over cultitypes and states, antiplatelet activity in 1995 was $9.7 \%$ lower than in 1994, illustrat- ing the influence of environmental factors in any given year on onion-induced antiplatelet activity. State wide, Wisconsin onion production was identical for both years. However, average yield was 38.1 tha ${ }^{-1}$ in 1994 , while in 1995 average yield was $26.3 \mathrm{t} \cdot \mathrm{ha}^{-1}$ (Wisconsin Agricultural Statistics Service, 1996). Average temperatures were $1{ }^{\circ} \mathrm{C}$ higher during the 1995 growing season then in 1994, but in August during the bulb fill stage temperatures were $5.3{ }^{\circ} \mathrm{C}$ cooler in 1994 . Average precipitation was $1.4 \mathrm{~cm}$ lower in 1995 compared to 1994, and in June 1994 during early plant development, precipitation was $9.5 \mathrm{~cm}$ higher. Freeman and Mossadeghi (1973) reported that water regime affects onion pungency. Slightly higher moisture conditions during 1994 with cooler temperatures during the bulb fill stage might have resulted in accumulation of ACSO, consequently accounting for increased antiplatelet activity.

INTERACTIONS INVOLVING THE POSTHARVEST STORAGE PERIOD (DATE). The MIXED analysis revealed high levels of significance for year, state, date, and cultitype main effects for antiplatelet activity, pungency and solids (Table 1). For antiplatelet activity, the main effects of year, cultitype, state, and date were highly significant $(P<0.001)$ in the order of the size of their $\mathrm{F}$ value, respectively. The most important interactions for antiplatelet activity were year $\times$ date, date $\times$ state, and year $\times$ date $\times$ state, with significance levels of $P<$ 0.001 for the first order interactions and $P<$ 0.01 for the second order interaction, respectively (Table 1). When the MIXED analysis for antiplatelet activity was performed with solids as a covariant, the effect of State became nonsignificant, indicating that factors causing differences in solids at each state might also affect antiplatelet activity (Table 1).

The year $\times$ date interaction was highly significant $(P<0.001)$ for antiplatelet activity as well as for pungency and solids. Averaged over states and cultitypes, mean antiplatelet activity was considerably higher at 130 and $170 \mathrm{~d}$ in postharvest storage during 1994 compared to 1995 (Figs. 1 and 2). In fact, the greatest antiplatelet activity during the 1994 postharvest storage period was reached at $170 \mathrm{~d}$, whereas that same point was reached at $90 \mathrm{~d}$ during the 1995 postharvest storage period (Figs. 1 and 2). The next first order interaction of critical importance was date $\times$ state. Averaged over cultitypes mean antiplatelet activity decreased in Oregon-grown bulbs from 130 to $170 \mathrm{~d}$ in postharvest cold storage, whereas during that same period, antiplatelet activity increased for Wisconsingrown bulbs. The year $\times$ date $\times$ state interactions were due to the change in rank of a particular state for a given year at the same storage period. These interactions illustrate that compounds influencing antiplatelet activity were likely affected by environmental factors and subject to genotype $\times$ environment interactions.

Pungency exhibited the same significantinteractions as antiplatelet activity, but the year $\times$ date $\times$ state interaction was of greater significance $(P<0.001$; Table 1$)$. Additionally, the year $\times$ state interaction was significant for pungency, reiterating the effects of environmental influences on pyruvic acid concentrations (Fig. 2). Soil chemical composition, temperature, and precipitation differ 
from state to state and can affect ratios of the ACSO in onion bulbs (Freeman and Mossadeghi, 1973; Randle et al., 1995). The differences between states were significant for bulb fresh weight but no correlation was observed when weight was analyzed as covariant for pungency (data not presented). Differences among states for volatile organosulfur contents of onion bulbs have long been established (Platenius and Knott, 1934) and soil sulfate concentration has in part been attributed to cause variation in bulb pungency (Freeman and Mossadeghi, 1970). Sharp decreases in enzymatically formed pyruvate at $210 \mathrm{~d}$ postharvest were noted for both 1994 and 1995. These decreases at the final sampling date may have been caused by bulb decay. Despite excellent storability for three out of four cultitypes used in this investigation, bulb decay is common past $150 \mathrm{~d}$ in postharvest cold storage. Bulb decomposition and cell leakage may have contributed to reduced pyruvate at the final sampling date. Increases in pyruvate from 90 to $170 \mathrm{~d}$ postharvest in 1994 and from 130 to 170 d postharvest in 1995 may have been the result of changes in enzymatic activity during bulb storage, such as increases in $\gamma$-glumatyl transpeptidase activity (Hanum et al., 1995).

Similar interactions were observed for soluble solids as were described for antiplatelet activity and pungency. Additionally, interactions such as date $\times$ cultitype and cultitype $\times$ location were also significant for soluble solids (Table 1). Changes in soluble solids during postharvest storage, and the effects of sulfur nutrition and environmental conditions on soluble solids have been well documented (Hurst et al., 1985; Mikitzel and Fellman, 1994;
Randle, 1992; Salama et al., 1990; Vavrina and Smittle, 1993). Significant changes in sugars are expected during metabolic processes in development, maturation, and postharvest stages of the bulb (Hurst et al., 1985; Randle, 1992; Vavrina and Smittle, 1993). Each of these processes can be affected by external influences such as cultitype, environments or genotype $\times$ environment interactions. Based on the number of significant interaction terms, soluble solids exhibited the largest amount of genotype $\times$ environment interaction of the three traits.

The date $\times$ state $\times$ cultitype interaction was significant for antiplatelet activity $(P<0.05)$. For pungency and soluble solids, this and other interactions with cultitype were observed. Pungency showed a significant $(P<0.01)$ year $\times$ date $\times$ cultitype interaction due to change in rank of cultitype from one sampling date to the next during postharvest storage and due to year effects. During the first year in storage (1994-95), antiplatelet activity increased 61\% across all cultitypes and states from 50 to $170 \mathrm{~d}$ in cold storage. During the second storage year (1995-96) antiplatelet activity increased by

Fig. 2. Mean antiplatelet activity of onion cultitype bulb extracts during a $210 \mathrm{~d}$ postharvest cold storage period, averaged over states for the 1994 harvest (A) and 1995 harvest (C). Antiplatelet activity was measured by percent aggregation in proportion to a nononion control. Mean pyruvate concentrations of onion cultitype bulb extracts during $210 \mathrm{~d}$ in postharvest cold storage, averaged over states for the 1994 harvest (B) and for the 1995 harvest (D). Ellipses around data points indicate nonsignificance at $P<0.05$ within storage date, based on the least square means analysis, among the cultitypes included in the ellipse.

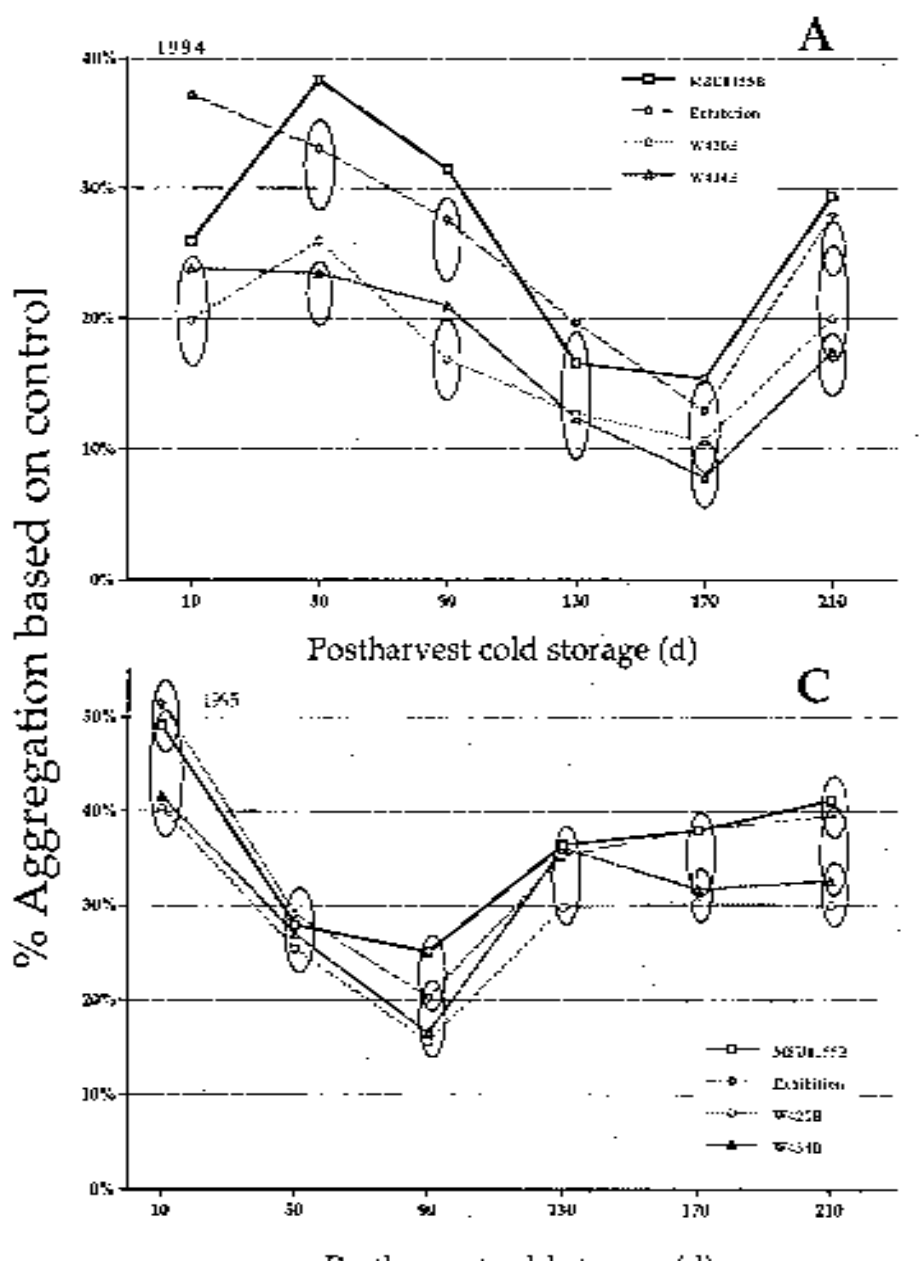

Postharvest cold storage \{d\}

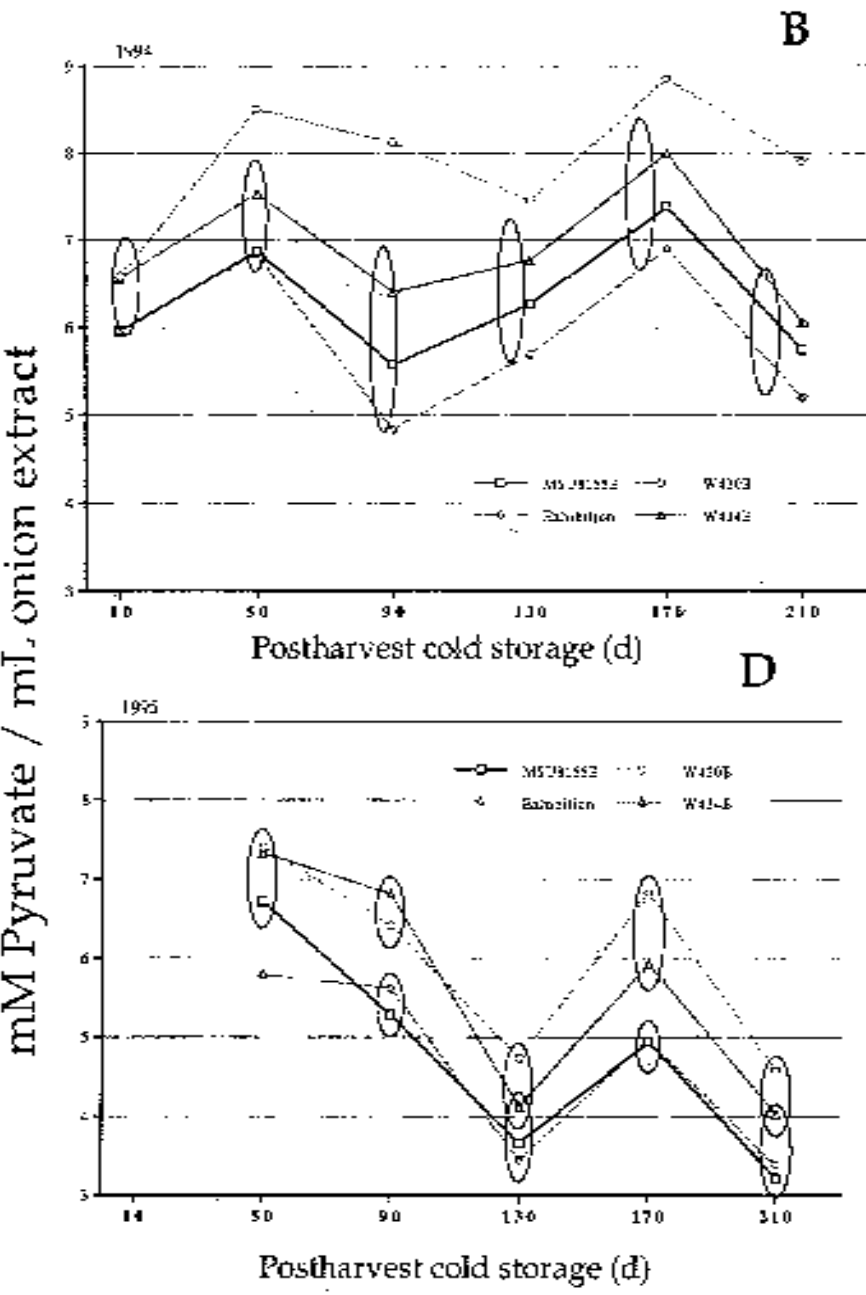

J. Amer. Soc. Hort. ScI. 124(4):366-372. 1999. 
Table 2. Least squares (LS) mean cultitype antiplatelet activity averaged over storage duration, states, and years with lower and upper $95 \%$ confidence intervals.

\begin{tabular}{lccc}
\hline \hline Cultitype & Lower & LS mean & Upper \\
\hline MSU8155B & 26.5 & $28.2 \mathrm{a}^{\mathrm{z}}$ & 29.9 \\
Exhibition & 25.0 & $26.7 \mathrm{a}$ & 28.3 \\
W420B & 18.9 & $20.4 \mathrm{~b}$ & 21.9 \\
W434B & 19.4 & $20.9 \mathrm{~b}$ & 22.4
\end{tabular}

${ }^{\mathrm{z} V a l u e s}$ with the same letter indicate nonsignificant differences among cultitype means at $P<0.05$.

$56 \%$ across all cultitypes in Wisconsin between 10 to $90 \mathrm{~d}$ in postharvest cold storage. Following the period of increase, antiplatelet activity decreased sharply (at 210 and 130 d for 1994 and 1995, respectively). Similarity in these patterns could be associated with physiological changes in bulbs during storage. Postharvest temperature conditions can influence onion plant development when bulbs are removed from storage and grown (Miedema, 1994). However, these conditions have not been studied systematically with respect to onion-induced antiplatelet activity. Brewster (1994) described a web of complex interactions among factors contributing to quality and sprouting of bulbs in postharvest storage conditions. In summarizing the main components influencing sprouting rates of stored bulbs, he listed seven prestorage factors that affect sprouting: cultivar, stage of bulb development during harvest, premature defoliation, skin integrity, conditions during ripening, harvesting, and curing. Hanum et al. (1995) measured an increase in $\gamma$-glumatyl transpeptidase activity in onion bulbs after $84 \mathrm{~d}$ of storage at ambient temperatures. This enzyme is responsible for converting $\gamma$-glumatyl peptides into the flavor precursors, or ACSOs, which in turn are hydrolyzed by alliinase to form bioactive thiosulfinates. Additionally, significant storage quality variability was documented, depending on year of production or postharvest handling (Vavrina and Smittle, 1993; Wall and Corgan, 1994). These physiological changes in the bulb during postharvest storage may be associated with transformation of organosulfur compounds in the storage organs to support regrowth.

No correlations among antiplatelet activity and pungency or antiplatelet activity and solids were significant. Similar to the study by Goldman et al. (1996), the more pungent cultitypes usually exhibited higher antiplatelet activity compared to the mild cultitypes. In a study that focused on flavor and quality changes in stored onion bulbs, investigators documented that, although pyruvate formation in macerated tissue of onion bulbs is correlated to pungency, pyruvate does not contribute directly to pungency or onion flavor (Mikitzel and Fellman, 1994). They further observed that in more mature bulbs from their second harvest, 3,4-dimethyl thiophene concentration remained constant while pyruvate increased during postharvest storage (Mikitzel and Fellman, 1994). Results herein agree with those of Mikitzel and Fellman (1994), which seem to indicate that pyruvate and thiosulfinates are affected differently during postharvest storage, perhaps triggered by physiological changes in the onion bulb. Additional investigations on the role of alliinase in converting the ACSO to pyruvate and the different sulfenic acids, which are precursors to the thiosulfinates, during development and postharvest storage might provide a better understanding of how these compounds and their ratios affect medicinal attributes and flavor characteristics of onion bulbs. Alternatively, Randle and colleagues (W.M. Randle, personal communication) have described significant changes in various ACSOs during postharvest storage of onion bulbs, such as an increase in 1-propenyl cysteine sulfoxide and a decrease in methyl cysteine sulfoxide during the storage period. Although ACSOs in garlic have not been associated with antiplatelet activity (Lawson, 1998), some evidence in onion (Morimitsu et al., 1992) suggests their association with platelet inhibition and documents different antiplatelet strenths for various ACSOs. If ACSO ratios changed during onion bulb storage, the presence of different thiosulfinates formed from ACSO decomposition at different times during the storage period may explain both antiplatelet activity flux and failure of these measures to correlate with pungency. Further investigation of the role of ACSO ratio changes and subsequent thiosulfinate formation during bulb storage should be conducted to verify this prediction.

Cultitypes responded similarly during postharvest storage conditions; i.e., all cultitypes had the lowest pyruvate concentration at $210 \mathrm{~d}$ and the highest antiplatelet activity at $90 \mathrm{~d}$ in postharvest storage for 1995 . Onion cultitypes used in this investigation clearly follow the same general pattern during postharvest storage.

Onion organosulfur compounds are synthesized through complex biochemical pathways. The individual sulfenic acids released following hydrolysis of ASCOs are highly reactive, changing spontaneously into the lachrymatory factor and thiosulfinates, which are further transformed spontaneously into more complex and stable molecules (Block, 1985). Many of the precursor, intermittent, and combinations of the final compounds can all individually or synergistically effect antiplatelet activity (Kawakishi and Morimitsu, 1994; Morimitsu et al., 1992). The complexity of the organosulfur chemistry of onions makes it difficult to control or predict antiplatelet activity in stored onion bulbs, and these data suggest that environmental conditions can contribute to the difficulty of this prediction.

In summary, data herein demonstrate that environmental factors and cultitype have an impact on in vitro onion-induced platelet aggregation and should be taken into consideration when clinical studies are proposed or when considering in vitro medicinal activity of onion.

Clinical trials will be required to determine if the health functionality of onion is affected by year, location, and cultitype effects. Enzymatically formed pyruvate determination was a good indicator for relative rankings of these cultitypes for antiplatelet activity. Thus, these pungent onions were generally higher in antiplatelet activity than mild onions. However, changes in enzymaticallyformed pyruvate were not correlated with changes in antiplatelet activity during postharvest storage, making pungency an unreliable indicator for measuring increases or decreases of antiplatelet activity during postharvest storage. Further, it is likely that preharvest environmental factors biased bulb pyruvate concentrations, solids and antiplatelet activity during postharvest storage. Additionally, genotype $\times$ environment interactions influenced pungency, soluble solids, and antiplatelet activity. Antiplatelet activity varied depending on cultitype, environment, and time in postharvest storage, which should be considered when evaluating onion bulbs for medicinal properties.

\section{Literature Cited}

Augusti, K.T. 1990. Therapeutic and medicinal values of onions and garlic, p. 93-108. In: H. Rabinovitch and J. Brewster (eds.). Alliums and allied crops. CRC Press, Boca Raton, Fla.

Augusti, K.T., M.E. Benaim, H.A. Dewar, and R. Virden. 1975. Partial identification of the fibrinolytic activators in onion. Atherosclerosis 21:409-416.

Bedford, L.V. 1984. Dry matter and pungency tests on British grown onions. J. Natl. Inst. Agr. Bot. 16:581-591. 
Block, E. 1985. The chemistry of garlic and onions. Sci. Amer. 252:114 120.

Block, E. 1992. The organosulfur chemistry of the genus Allium-Implications for the organic chemistry of sulfur. Angewante Chemien. 31:11351178.

Born, G.V.R. and M.J. Cross. 1963. The aggregation of blood platelets. J. Physiol. 168:178-195.

Brewster, J.L. 1994. Onions and other vegetable Alliums. CAB Intl., Cambridge, England.

Freeman, G.G. and N. Mossadeghi. 1970. Effects of sulphate nutrition on flavor components of onion (Allium cepa). J. Sci. Food Agr. 21:610-615.

Freeman, G.G. and N. Mossadeghi. 1973. Studies on the relationship between water regime and flavour strength in water cress (Rorippa nasturium-aquaticum [L.] Hayek), cabbage (Brassica oleracea var. Capitata) and onion (Allium cepa). J. Hort. Sci. 48:365-378.

Goldman, I.L. 1996. A list of germplasm releases from the University of Wisconsin Onion Breeding Program, 1957-1993. HortScience 31:878879.

Goldman, I.L., B.S. Schwartz, and M. Kopelberg. 1995. Variability in blood platelet inhibitory activity of Allium (Alliaceae) species accessions. Amer. J. Bot. 82:827-832.

Goldman, I.L., M. Kopelberg, and J.E.P. Debaene. 1996. Onion antiplatelet activity is sulfur dependent. Thrombosis and Haemostasis. 76:450-452.

Hanum T., N.K. Sinha, and J.N. Cash. 1995. Characteristics of $\gamma$-glutamyl transpeptidase and alliinase of onion and their effect on the enhancement of pyruvate formation in onion macerates. J. Food Biochem. 19:51-65.

Hosfield, G.L., G. Vest, and C.E. Peterson. 1977. A seven-parent diallel cross in onions to evaluate general and specific combining ability and their interaction with years and locations. J. Amer. Soc. Hort. Sci. 102:56-61.

Hurst, W.C., R.L. Shewfelt, and G.A. Schuler. 1985. Shelf-life and quality changes in summer storage onions (Allium cepa). J. Food Sci. 50:761764.

Kawakishi, S. and Y. Morimitsu. 1994. Sulfur chemistry of onions and inhibitory factors of the arachidonic acid cascade, p. 120-127. In: M.-T. Huang (ed.). Food phytochemicals for cancer prevention. I: Fruits and vegetables. Amer. Chem. Soc., Washington, D.C.

Kopsell, D.E and W.M. Randle. 1997. Onion cultivars differ in pungency and bulb quality changes during storage. HortScience 32:1260-1263.

Lancaster, J.E. and M.J. Boland. 1990. Flavor biochemistry, p. 33-72. In: H. Rabinovitch and J. Brewster (eds.). Alliums and allied crops. CRC Press, Boca Raton, Fla.

Lancaster, J.E. and M.L. Shaw. 1989. $\gamma$-Glutamyl peptides in the biosynthesis of S-alk(en)yl-L-cysteine sulphoxides (flavour precursors) in Allium. Phytochemistry 28:455-460.

Lancaster, J.E. and M.L. Shaw. 1991. Metabolism of $\gamma$-glutamyl peptides during development, storage, and sprouting of onion bulbs. Phytochemistry 30:2857-2859.

Lawson, L.D. 1993. Bioactive organosulfur compounds of garlic and garlic products: Role in reducing blood lipids, p. 306-330. In: A.D. Kinghorn and M.F. Balandrin (eds). Amer. Chem. Soc., Washington, D.C.

Lawson, L.D. 1998. Garlic: A review of its medicinal effects and indicated active compounds, p. 176-209. In: L.D. Lawson and R. Bauer (eds). Phytomedicines of Europe. Amer. Chem. Soc., Washington, D.C.

Littell, R.C., G.A. Milliken, W.W. Stroup, and R.D. Wolfinger. 1996. SAS system for mixed models. SAS Inst. Inc., Cary, N.C.
Mann, L.K. and B.J. Hoyle. 1945. Use of the refractometer for selecting onion bulbs high in dry matter for breeding. Proc. Amer. Soc. Hort. Sci. 46:285-292.

Miedema, P. 1994. Bulb dormancy in onion. I. The effects of temperature and cultivar on sprouting and rooting. J. Hort. Sci. 69:29-39.

Mikitzel, L.J and J.K. Fellman. 1994. Flavor and quality changes in sweet onions during storage at room temperature. J. Food Quality. 17:431-445.

Morimitsu, Y. and S. Kawakishi. 1990. Inhibitors of platelet aggregation from onion. Phytochemistry. 29:3435-3439.

Morimitsu, Y, Y. Morioka, and S. Kawakishi. 1992. Inhibitors of platelet aggregation generated from mixtures of Allium species and/or S-alk(en)nylL-cysteine sulfoxides. J. Agr. Food Chem. 40:368-372.

Mustard, J.F. and M.A. Packham. 1970. Factors influencing platelet function: Adhesion, release, and aggregation. Pharmacol. Rev. 22:97187.

Patil, B.S., L.M. Pike, and B.K. hamilton. 1995a. Changes in quercitin concentration in onion (Allium cepa $\mathrm{L}$.) owing to location, growth stage and soil type. New Phytol. 130:349-355.

Patil, B.S., L.M. Pike, and K.S. Yoo. 1995b. Variation in quercitin content in different colored onions (Allium cepa L.). J. Amer. Soc. Hort. Sci. 120:909-913.

Platenius, H. and J.E. Knott. 1934. Pungency of onions in relation to variety and ecological factors. Proc. Amer. Soc. Hort. Sci. 32:593-595.

Randle, W.M. 1992. Onion germplasm interacts with sulfur fertility for plant sulfur utilization and bulb pungency. Euphytica 59:151-156.

Randle,W.M. and M.L.Bussard. 1993a. Sulfurnutrition affects nonstructural water-soluble carbohydrates in onion germplasm. HortScience 27:5255.

Randle, W.M. and M.L. Bussard. 1993b. Pungency and sugars of shortday onions as affected by sulfur nutrition. J. Amer. Soc. Hort. Sci. 118:766-770.

Randle W.M., J.E. Lancaster, M.L. Shaw, K.H. Sutton, R.L. Hay, and M.L. Bussard. 1995. Quantifying onion flavor compounds responding to sulfur fertility-Sulfur increases levels of alk(en)yl cysteine sulfoxides and biosynthetic intermediates. J. Amer. Soc. Hort. Sci. 120:1075-81.

Salama, A.C., J.R. Hicks, and J.F. Nock. 1990. Sugar and organic acid changes in stored onion bulbs treated with maleic hydrazide. HortScience 25:1625-1628.

Schwartz, B.S. and M.C. Monroe. 1986. Human platelet aggregation is initiated by peripheral blood mononuclear cells exposed to bacterial lipopolysaccharide in vitro. J. Clin. Invest. 78:1136-1141.

Schwimmer, S. and W.J. Weston. 1961. Enzymatic development of pyruvic acid in onion as a measure of pungency. J. Agr. Food. Chem. 9:301-304.

Suzuki, M. and J.A. Cutliffe. 1989. Fructans in onion bulbs in relation to storage life. Can. J. Plant Sci. 69:1327-1333.

Utkhede, R.S., J.E. Rahe, J.R. Coley-Smith, Q.P. Van der Meer, J.G. Brewer, and V. Criscola. 1982. Genotype-environment interactions for resistance to onion white rot. Can J. Plant Pathol. 4:269-271.

Vavrina, C.S. and D.A. Smittle. 1993. Evaluating sweet onion cultivars for sugar concentrations and pungency. HortScience 28:804-806.

Wall, M.M. and J.N. Corgan. 1994. Postharvest losses from delayed harvest and during common storage of short-day onions. HortScience 29:802-804.

Wisconsin Agricultural Statistics Service. 1996. Wisconsin agricultural statistics. Wis. Agr. Stat. Serv., Madison, Wis. 